\title{
Change in Financial Stress and Relational Wellbeing During COVID-19: Exacerbating and Alleviating Influences
}

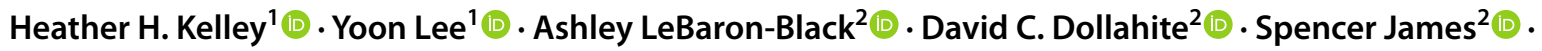 \\ Loren D. Marks ${ }^{2}$ (D) Tyler Hall ${ }^{3}$
}

Accepted: 12 January 2022 / Published online: 9 February 2022

(c) The Author(s), under exclusive licence to Springer Science+Business Media, LLC, part of Springer Nature 2022

\begin{abstract}
Guided by the family adjustment and adaptation response (FAAR) model and using a panel survey of 1510 adults in the US administered during the summer of 2020 and a mixed methods approach, we explored associations between changes in financial stress related to COVID-19 and relational wellbeing. Regression analyses showed that, compared to those who maintained their levels of financial stress, those who reported increased financial stress reported increased conflict and those who reported decreased financial stress reported decreased conflict. However, decreased financial stress was also associated with decreases in emotional closeness and relationship happiness, suggesting that changes in financial stress can lead to both maladaptation and bonadaptation in families. Qualitative findings provide insights into factors that may exacerbate or help alleviate financial stress related to COVID-19.
\end{abstract}

Keywords Financial stress · COVID-19 $\cdot$ Relational wellbeing $\cdot$ Family adjustment and adaptation response $\cdot$ Family finance

Finances matter a great deal for various aspects of couple and family relationships and wellbeing (Dew, 2020; Kelley et al., 2020). Finances have been consistently identified as

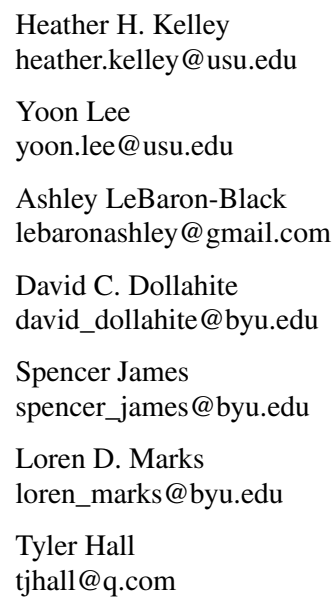

1 Department of Human Development and Family Studies, Utah State University, Logan, USA

2 School of Family Life, Brigham Young University, Provo, USA

3 School of Child and Family Sciences, University of Southern Mississippi, Hattiesburg, MS, USA one of the top stressors for both individuals and relationships in America (APA, 2015, 2019). The COVID-19 pandemic and its associated lockdowns and restrictions have created widespread economic challenges which, for many, have led to increased financial stress (NEFE, 2020).

Given the associations between financial stress and family relationships, the primary purpose of this study is to explore how changes in financial stress related to COVID-19 influence family relationships. Utilizing the family adjustment and adaptation response (FAAR) model (Patterson, 1988) as our theoretical framework, we also aim to explore the specific issues that exacerbated financial stress during COVID19 , as well as behaviors, resources, and meanings that helped alleviate or reduce financial stress during this time.

\section{Theoretical Framework}

This study utilizes Patterson's (1988) family adjustment and adaptation response (FAAR) model to frame the analysis and interpret the results (see Fig. 1). The FAAR model posits that families are constantly striving to achieve or maintain a balance between their demands (i.e., stressors) and their capabilities (i.e., resources). Meanings, which encompass 
Fig. 1 The FAAR model (Patterson, 1988) adapted for the current study

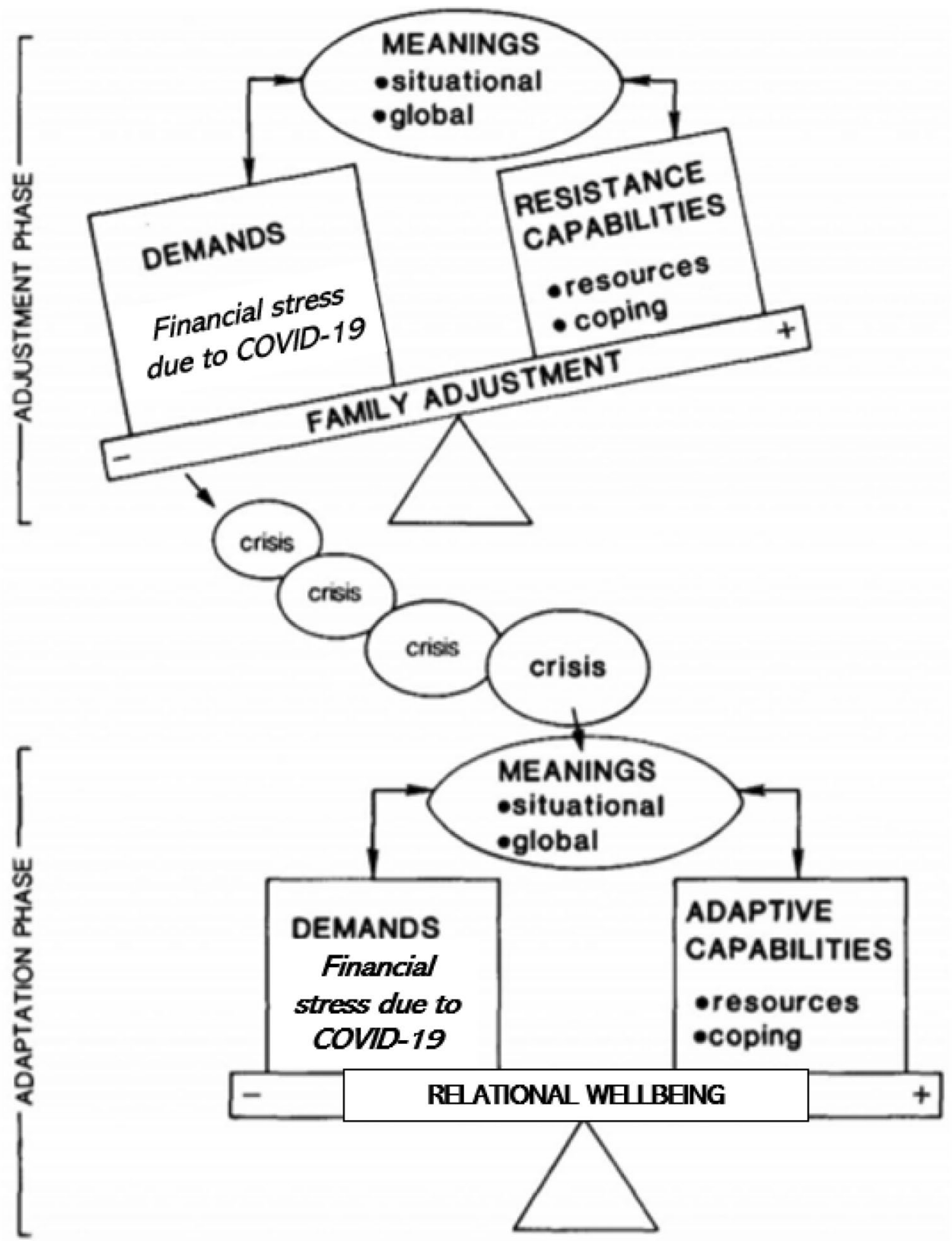

how family members view their demands and capabilities, can have an important influence on how families are able to balance their demands and capabilities. For example, resilient perspectives regarding demands (e.g., ability to find purpose in struggle, ability to think of struggles as opportunities for growth) can help families cope and achieve rebalance more easily. Most of the time, families reside in the adjustment phase, where they are able to continually make small adjustments to balance their demands and capabilities and maintain an equilibrium. In other words, the adjustment phase is focused on minor disruptions to this equilibrium, where demands can be counterbalanced by capabilities (i.e., families draw on available resources to meet demands and cope with stressors) and there is no serious disruption to the family system.

In contrast to this day-to-day balancing act, when families face overwhelming demands that cannot be balanced with their current capabilities, major disruption to the equilibrium occurs and they experience crisis (Patterson, 1988). This crisis places families in the adaptation phase. In the adaptation phase, families must make more drastic changes to their demands, capabilities, and meanings to achieve a new equilibrium within their family. Changes must be more drastic in this phase because the pileup of demands and subsequent disruption of the equilibrium were more drastic. During this adaptation stage, families can either change in ways that 
decrease or threaten family wellbeing (termed maladaptation) or change in ways that increase or promote family wellbeing (termed bonadaptation). In both cases, a new equilibrium is reached out of necessity. However, maladaptation can create new vulnerabilities, whereas bonadaptation can potentially lead to even higher levels of wellbeing than were experienced before crisis occurred. In sum, when families are faced with overwhelming demands and experience crisis, they must either alleviate their demands, acquire more or improve their capabilities, and/or change their meanings to obtain a new equilibrium, and the ways in which families adapt can either help or hinder their wellbeing.

In line with both Pietromonaco and Overall's (2020) and Prime et al.'s (2020) conceptual frameworks related to families and COVID-19, we posit that the COVID-19 pandemic placed new demands on many families that were overwhelming in terms of quantity and quality. Many families did not have adequate capabilities or meanings to deal with these demands, so they experienced crisis and entered the adaptation phase (Patterson, 1988). As families have sought to adapt to achieve a new equilibrium, some have achieved bonadaptation while some have experienced maladaptation. One type of demand that families have experienced due to COVID-19 is financial stress (i.e., an increase in financerelated stressors, such as loss of income and housing insecurity, due to the pandemic). One marker of maladaptation is decreased relational wellbeing, while a marker of bonadaptation is increased relational wellbeing (see Fig. 1). In the current study, we will first quantitatively examine how COVID-19 related changes in financial stress influence several indicators of relational wellbeing (relational conflict, emotional closeness, couple relationship happiness). Because a lack of alleviating demands during the adaptation phase can lead to maladaptation (Patterson, 1988), we will hypothesize that increased financial stress due to COVID19 will be associated with increased relational conflict and decreased family emotional closeness and relationship happiness (i.e., maladaptation). On the other hand, because alleviating demands during the adaptation phase can lead to bonadaptation (Patterson, 1988), we will hypothesize that decreased financial stress due to COVID-19 will be associated with decreased relational conflict and increased emotional closeness and relationship happiness (i.e., bonadaptation). Then, we will qualitatively explore other demands, capabilities, and meanings that facilitated or detracted from families' ability to achieve bonadaptation following crisis.

\section{Literature Review}

\section{Economic Impact of COVID-19 in the US}

For many, the financial ramifications of the COVID-19 pandemic have ranged from increased uncertainty to a devastating loss of income, housing, and security. In the weeks immediately following COVID-19 related closures and restrictions, from March 15th to April 9th 2020, over 17 million Americans filed for unemployment (Long \& Dam, 2020). National unemployment rates, typically between 3.5 and $3.7 \%$ prior to the COVID-19 pandemic reached a high of $14.7 \%$ in April, 2020 and were at $6.7 \%$ as of December, 2020 (U.S. Bureau of Labor Statistics, 2021). One survey showed that as many as $17 \%$ of Americans claimed to have lost their job due to the pandemic and 23\% reported a pay cut. Overall, $43 \%$ of Americans claimed that they or someone in their household lost a job or income due to the pandemic (Igielnik, 2020).

During the initial months of the COVID-19 closures (March-April, 2020) substantial drops and increased instability in the stock market resulted from the COVID-19 pandemic and drops in the stock market appeared to be associated with increases in the number of cases (Ashraf, 2020). The prolongation of the pandemic and its related closures appears to be associated with increased stock market volatility (Albulescu, 2020). For many Americans, the stock market volatility directly harmed their investments and retirement accounts during the initial months of COVID-19 (Croce, 2020). Over a year after the onset of COVID-19, the stock market has bounced back and regained many losses. However, the recovery has been "far from even, and many industries... remain down significantly from their prepandemic peaks," (Bradley \& Stumpner, 2021). More concerningly, the initial income shocks from COVID-19 were strongest for the those in lower income brackets, while income shocks for those with high incomes were negligible, exacerbating already-deep inequalities (Hanspal et al., 2020).

With all the various financial stressors that COVID-19 and the related lockdowns have created or exacerbated, as would be expected, there have been drastic increases in reports of financial stress in the US. A survey conducted in April 2020 of 2018 adults found that 9 out of 10 Americans reported that COVID-19 was causing them personal financial stress (NEFE, 2020). The Center for Disease Control and Prevention noted that increased financial stress may result from COVID-19-related restrictions and suggested general coping techniques, such as taking care of one's physical health, taking time to unwind, and connecting with others, to help manage increases in stress related to COVID19 (CDC, 2020). 


\section{COVID-19 and Family Relationships}

Research on the impact of COVID-19 on family relationships is just emerging. Several studies have suggested that COVID-19 is associated with increased stress and conflict in relationships (e.g., Brown et al., 2020; Douglas et al., 2020). While more data and research are needed on the impacts of COVID-19 on families, several scholars have also looked to past research and developed conceptual frameworks of how this pandemic and its related restrictions will impact families. Pietromonaco and Overall (2020) suggested that stress related to COVID-19 will likely increase or exacerbate harmful processes (e.g., negativity/hostility, withdrawal, diminished support, etc.) in intimate relationships. Specifically, they highlighted how preexisting contextual vulnerabilities (e.g., SES, marginalized group member, age, etc.) and individual vulnerabilities (e.g., attachment insecurity, mental and emotional health, etc.) can interact with external stressors (e.g., economic strain, lack of childcare, isolation, etc.) that have been created or exacerbated by the COVID19 pandemic. They argued that when these vulnerabilities and stressors interact and lead to couples relying on "less adaptive relationship processes," this would diminish couple relationship quality and decrease the stability of the relationship (pp. 441-442).

Prime et al. (2020) also argued in their conceptual framework that families with preexisting vulnerabilities are more likely to be harmed by the pandemic and its repercussions as these vulnerabilities "increase susceptibility to social disruptions and the sequelae of the pandemic" (p. 2). However, Prime and colleagues also presented the idea that challenges and crises can strengthen relationships, referring to this concept as "posttraumatic growth-the ability not just to survive but to thrive in the face of adversity" (p. 634, emphasis in original). In particular, they highlighted "(a) meaningmaking of adversity, (b) fostering a positive outlook, and (c) transcendence and spirituality" as processes that can help individuals and families grow and become closer when faced with difficulties, as these processes can help families "embrace hope" and foster feelings of shared "family agency" during difficult times (p. 639). Other scholars also have recognized that despite the danger of the COVID-19 virus and the difficulties in adjusting to changes wrought by the pandemic, these changes can have positive influences on relationships, such as increased time together as family and additional options for virtual connection. Family psychologist Jay Lebow quoted Dicken's renowned line, "It was the best of times; It was the worst of times" as he discussed both the potential costs (e.g., loss of life, threats to health, financial challenges, etc.) and benefits (e.g., new ways of connecting with family and community members) of this pandemic to family relationships (2020, p. 309).

\section{Financial Stress and Relational Wellbeing}

The negative influence of financial stress on marital relationships and wellbeing has been well documented. Across studies, various financial stressors, such as debt and ability to pay bills, as well as perceived financial stress have been found to predict lower levels of marital satisfaction and marital quality (Archuleta et al., 2011; Dew \& Xiao, 2013; Gudmunson et al., 2007; Stewart et al., 2017), and higher rates of marital distress and divorce (Conger et al., 1990; Dew, 2011; Dew et al., 2012). This potential negative impact might be considered relational maladaptation. A recent meta-analysis of 29 independent samples $(N=34,007$ participants) found a negative relationship between economic strain and functioning in intimate relationships that existed independent of gender, education, race/ethnicity, and study/ sample design (Falconier \& Jackson, 2020). In addition to the negative associations between financial stress and intimate relationships, research has also suggested that financial stress has the potential to increase parents' depressive symptoms and is associated with poorer developmental outcomes for children (Conger et al. 2020; Lee et al., 2011; Mistry et al., 2008). Research suggests that the indirect effects of financial challenges, such as changes to one's attitude, mood, and behavior towards one's partner or others, that are caused by their financial situation (Conger et al., 2000; Vinokur et al., 1996) may be just as detrimental to relationships as the direct effects of financial strain (Kinnunen \& Feldt, 2004; Robila and Krishnakumar 2005) as they may lead to increased hostility, conflict, and aggression (Aytaç \& Rankin, 2009; Falconier \& Epstein, 2011).

Despite the potential direct and indirect negative effects of financial stress on relationships, there are several constructs, such as couple communication and co-parenting practices, that have been shown to moderate the negative relationship between financial stress and various facets of family relationships (Kelley et al., 2018; Mao, 2017). For example, Kelley et al. found that the effect of financial stress on marital quality was less negative when paired with positive communication while Mao found that positive coparenting skills diminished some of the negative effects of financial stress on parenting quality. Thus, there are various processes that have the potential to act as protective factors for couples and family against such influences.

Further, research suggests that when couples enact relationship maintenance behaviors (i.e., regular acts of kindness and affection towards each other, such as making coffee for partner or asking about partner's day) and receive financial support from friends/family, financial stress can even have a positive influence on relationships (Dew et al., 2018; LeBaron et al., 2020). Indeed, it seems that as long as couples have sufficient relational resources (i.e., relationship maintenance behaviors) and financial resources (i.e., financial 
support) to successfully cope with their financial stressors, these stressors can be catalysts for relational growth (i.e., relational bonadaptation; Dew et al.; LeBaron et al.). Perhaps financial stressors might provide couples with an opportunity to work through challenges together and subsequently increase their commitment to each other (Dew et al.; LeBaron et al.).

\section{Hypotheses}

We are interested in exploring how COVID-19 related changes in financial stress influence relational wellbeing. In applying the FAAR model (Patterson, 1988) to this research question, we look at change in financial stress as a demand and look at how families adapted to financial stress through several measures of family wellbeing (relational conflict, emotional closeness, couple relationship happiness). Based on the reviewed literature, Prime et al.'s (2020) conceptual framework, and the FAAR model, we offer the following hypotheses:

H1 We hypothesize that compared to those whose financial stress remained the same, increases in financial stress related to COVID-19 will be associated with maladaptation, conceptualized as increased relational conflict and decreased family emotional closeness and relationship happiness.

H2 We hypothesize that compared to those whose financial stress remained the same, decreases in financial stress will be associated with bonadaptation, conceptualized as decreased relational conflict and increased emotional closeness and relationship happiness.

Additionally, we use qualitative data to identify potential demands, capabilities, and meanings that facilitated or detracted from bonadaptation when coping with financial stress related to COVID-19. Given the qualitative and exploratory nature of this second research question, we refrain from making specific hypotheses (Marks, 2015).

\section{Methods}

\section{Data}

The data used in this study comes from a panel survey focused on family processes during the COVID-19 pandemic. Data collection took place between June 18 and July 22, 2020. Participants were contacted and compensated through Qualtrics. Selection criteria included being 18 years of age or older, residing in the United States, and speaking English. The survey was primarily comprised of close-ended quantitative questions with several optional open-ended questions. After obtaining approval from the Institutional Review Broad, participants were recruited through Qualtrics Professional Research Panel. The survey took, on average, $25 \mathrm{~min}$ to complete. To reduce self-selection bias, the survey invitation did not provide details regarding the content of the survey but rather informed potential participants that the survey was for research purposes only, of the approximate length of the survey, and of the incentive for completing the survey. No identifying information was collected by the researchers.

Qualtrics's professional research panel guarantees highquality data (Qualtrics, 2021) and several attention check questions were employed to filter out careless responders. First, we included two directed-response items throughout the survey. These questions, in which respondents are instructed how they should respond, provide a clear metric by which to measure participant attentiveness (Meade \& Craig, 2012). Additionally, at the end of the survey, we included a dichotomous measure from Meade and Craig asking, "In your honest opinion, should we use your data in our analyses in this study?" (p. 442), which the authors found was an effective method to screen out some careless responders. In an attempt to reduce concerns that removing respondents based on failed attention checks may introduce a demographic bias to the data (Vannette, 2017), respondents were only automatically filtered out if they responded incorrectly or negatively to at least two of these three items and we employed the following post-hoc methods to further filter out careless responses: For respondents that missed only one of these three items, their data was manually reviewed to identify straight-liners or nonsensical responses. Additionally, we looked for speeders and duplicate responses and removed responses where appropriate. Approximately 19\% of the sample was identified as careless responders and was replaced by Qualtrics Professional Research Panel. Despite our efforts to improve the quality of the our data, we note that there remain limitations to online data collection methods, including selection bias in regards to those who choose to complete online surveys; however, Qualtrics panel most closely resembles the demographic makeup of the US and their database includes over 100 million people recruited from various sources (Heen et al., 2014).

\section{Sample}

The sample is comprised of 1,510 adults from across the United States (from 40 states). Half of participants were female. Participants ranged in age, with $12.9 \%$ between 18-29 years, $22.7 \%$ between $30-39$ years, $29 \%$ between $40-49$ years, $6.6 \%$ between $50-59$ years, $14.8 \%$ between $60-69$ years, and $14.1 \%$ were over 70 years of age. Regarding sexual orientation, $89.6 \%$ of the sample was heterosexual, and the remaining $10.4 \%$ were sexual minorities. 
The majority of the sample (i.e., $70.5 \%)$ were married (2\% were cohabiting and the remaining were currently single), and $70.1 \%$ of the sample were parents. Sixty percent of the sample was White, $17.8 \%$ was Asian, $9.9 \%$ was Black, 9.3\% was Hispanic, and $3 \%$ was other or preferred not to disclose their race/ethnicity.

Overall, the sample was highly educated: $32.3 \%$ had a master's degree or higher, $40.1 \%$ had a bachelor's degree, $6 \%$ completed trade school, $20.7 \%$ completed high school, with the remainder having some high school or less. Regarding annual household income, $31.7 \%$ of families reported making less than $\$ 59,999,28.7 \%$ reported income in the $\$ 60,000-99,000$ range $20.1 \%$ reported income in the $\$ 100,000-149,000$ range, with the final $18.5 \%$ making $\$ 150,000$ or more per year. At the time of the survey, states and cities across the US were at various stages of reopening following COVID-19-related closures. The majority of the sample reported that their state or city was in the yellow $(48.3 \%)$ or orange $(33.9 \%)$ stage of reopening, while $6.6 \%$ reported they were still in the red stage and $11.2 \%$ were in the green stage. ${ }^{1}$

\section{Variables}

\section{Dependent Variables}

To measure relational wellbeing, we utilized three measures that assess different aspects of relational wellbeing, specifically relational conflict, emotional closeness, and relationship happiness, as described below.

Relational Conflict We asked participants about the relational conflict in their family ("How much relational conflict existed/exists in your family?") on a ten-point scale ranging from 1 (no relational conflict at all) to 10 (a great deal of relational conflict) at three phases: before the COVID19 related shutdowns, during the height of the COVID-19

\footnotetext{
1 This was measured through asking the following question: "States and cities across the country have implemented various plans for reopening following COVID-19 closures based on current risk levels. Many have assigned colors from Red to Green represent the risk level and precautions they are taking. Which of the following BEST describes the current conditions where you live?

Red - Only essential businesses are open. All nonessential workers are to remain home.

Orange - Some nonessential businesses and public places have been allowed to reopen under strict guidelines, while other nonessential businesses and public places have remained closed. Gatherings are still limited to approximately 10-20 people.

Yellow - Most nonessential businesses and public places have been reopened. Some restrictions have been reduced or lifted. Additional restrictions are still in place.

Green - The new normal. Businesses have reopened and large gatherings are allowed. Temporary restrictions have primarily been lifted. However, some restrictions or policies may remain indefinitely.".
}

related shutdowns, and currently, indicating the timepoint at which the survey was taken.

Emotional Closeness We asked participants about their perceived emotional closeness with their family ("How emotionally close would you describe your relationships with your family as being?") on a ten-point scale ranging from 1 (not at all close) to 10 (extremely close) at three phases: before the COVID-19 related shutdowns, during the height of the COVID-19 related shutdowns, and currently.

Relationship Happiness For participants who reported being married or cohabiting $(n=1,062)$, we asked, "How would you rate your happiness in your relationship?" on a ten-point scale ranging from 1 (not at all close) to 10 (extremely close) at three phases: before the COVID-19 related shutdowns, during the height of the COVID-19 related shutdowns, and currently.

\section{Independent Variables}

Change in Financial Stress We asked participants, "How would you rate your financial stress?" Participants retrospectively responded to this on a ten-point scale ranging from 1 (none at all) to 10 (a great deal) at three phases: before the COVID-19 related shutdowns, during the height of the COVID-19 related shutdowns, and currently. ${ }^{2}$ Using a tabulation of participants' reports of their financial stress before COVID-19 and during the height of COVID-19 shutdown, we created a categorical variable that measured whether or not participants decreased, maintained, or increased in financial stress.

Demographic Variables In our statistical analyses, we controlled for a number of sociodemographic variables including household income, education, sex, race/ethnicity, age, and marital status. Additionally, we controlled for other less traditional yet highly relevant factors, including participants' city's stage of reopening following COVID-19

\footnotetext{
${ }^{2}$ Given the unanticipated nature of the COVID-19 pandemic, we were unable to collect true longitudinal data on these questions. As such, we opted to collect retrospective responses regarding their financial stress and relational wellbeing before COVID-19 and during the height of COVID-19 related shutdowns on a variety of measures in addition to their current wellbeing and behaviors. While current attitudes may influence participants' recollections of their past wellbeing and behaviors (Miller and Gallagher 2009), asking about the different time-points simultaneously is helpful in understanding how participants viewed the impact of COVID-19 at the time of the survey and their perception of how they had changed because of it. Previous research has suggested that retrospective measures of pre-event outcomes measured simultaneously with post-event outcomes may be more effective than traditional pre-test/post-test methods at identifying how participants view the impact of a program or event (Lam and Bengo 2003; Levinson et al. 1990). Such methods have been effectively used in the past to understand the impact of a crisis (e.g., the terrorist attacks on September 11, 2001) on various facets of life (Seirmaco et al. 2012).
} 
shutdowns using a subjective measure in which participants rated the current level of restrictions where they reside. As this sample had a high number of religious individuals, and religion can both exacerbate (e.g., increasing time and financial obligations) and alleviate financial stress (e.g., reduce materialism and foster positive views on financial struggles; LeBaron et al., 2019), we also controlled for religiosity using a subjective measure of how religious participants considered themselves to be.

\section{Data Analyses}

\section{Why Mixed Methods}

In their review of 40 articles from the past decade related to finances and family matters, Kelley et al. (2020) identified that only $10 \%$ of the reviewed articles utilized a qualitative approach, while none employed mixed methods, and highlighted the need for more diverse methods to investigate associations between finances and family issues. While quantitative methods are needed to understand trends and the prevalence of behaviors, qualitative methods can help increase understanding of the why behind behaviors (Yoshikawa et al., 2008). Further, combining quantitative and qualitative findings can often add a more nuanced understanding of patterns by highlighting and examining incongruent findings, which is important in examining complex issues (Yoshikawa et al.).

\section{Quantitative Data Analysis}

We first ran descriptive statistics, after which we created a correlation matrix (see Table 1) to assess the bivariate associations between COVID-19-related changes in financial stress and relational wellbeing (relational conflict, emotional closeness, and relationship happiness) as well as our control variables. Regression analyses were run in Stata 16 (StataCorp, 2019) to assess the research questions (see Table 2). To assess associations between changes in financial stress and changes in relational wellbeing, we controlled for the before levels of family closeness, family conflict, and relationship happiness as we looked at the current levels of family closeness, family conflict, and relationship happiness as our outcome variables. This approach allowed us to determine how those who increased or decreased in financial stress changed in relational wellbeing compared to how those who maintained their before levels of financial stress changed on these measures of relational wellbeing. Additionally, we controlled for the following potentially confounding variables: age, sex, education, income, race/ ethnicity, religiosity, and stage of city/state reopening.

\section{Qualitative Data Analysis}

Responses to, "Do you have any related thoughts or experiences regarding how financial stress related to COVID-19 impacted you or your family? What helped you cope with this financial stress?" were analyzed and coded using NVivo 12 software. There were 648 participants who provided a useable response related to how their financial stress had been exacerbated or what they had done to alleviate or cope with their financial stress during the pandemic. Of these, 411 participants provided responses related to what helped alleviate their financial stress while 349 participants discussed what exacerbated their financial stress; 112 participants provided information on both the alleviating and exacerbating influences. To measure whether those who provided useable responses to this optional question differed from those who did not, we ran t-tests and chi-square tests on a number of key demographic variables (i.e., income, education, race, having children, marital status, gender, and stage of reopening). We did not identify any significant differences between these groups.

A team-based approach to coding was used in order to reduce the biases of a single coder and to measure interrater reliability (Marks, 2015). The first author reviewed the responses to identify themes and worked with two other coders to create a codebook of the identified themes. Specifically, the first author and the two coders reviewed a portion (approximately 15\%) of the responses independently and created a list of the common themes. The first author and coders then shared their results and discussed which themes should be included in the codebook and which themes should be combined with other themes. The first author then created a codebook which the other coders reviewed and provided feedback on (see Marks 2015 for a more detailed description of this process). This codebook was then given to two additional coders who used it to code all of the accounts. To assess interrater reliability, all accounts were coded independently by each of the coders (Levitt et al., 2018; Marks 2015); Cohen's kappa, calculated in NVivo 12, was 0.67, indicating substantial agreement (Landis \& Koch 1977).

\section{Quantitative Findings}

Means, standard deviations, and bivariate correlations can be found in Table 1. Bivariate correlations show significant associations between financial stress and each of our outcome variables (relational conflict, emotional closeness, and relationship happiness). From retrospective accounts of before COVID-19 to during the height of COVID-19, 15.6\% of participants reported decreased financial stress, $48.7 \%$ 


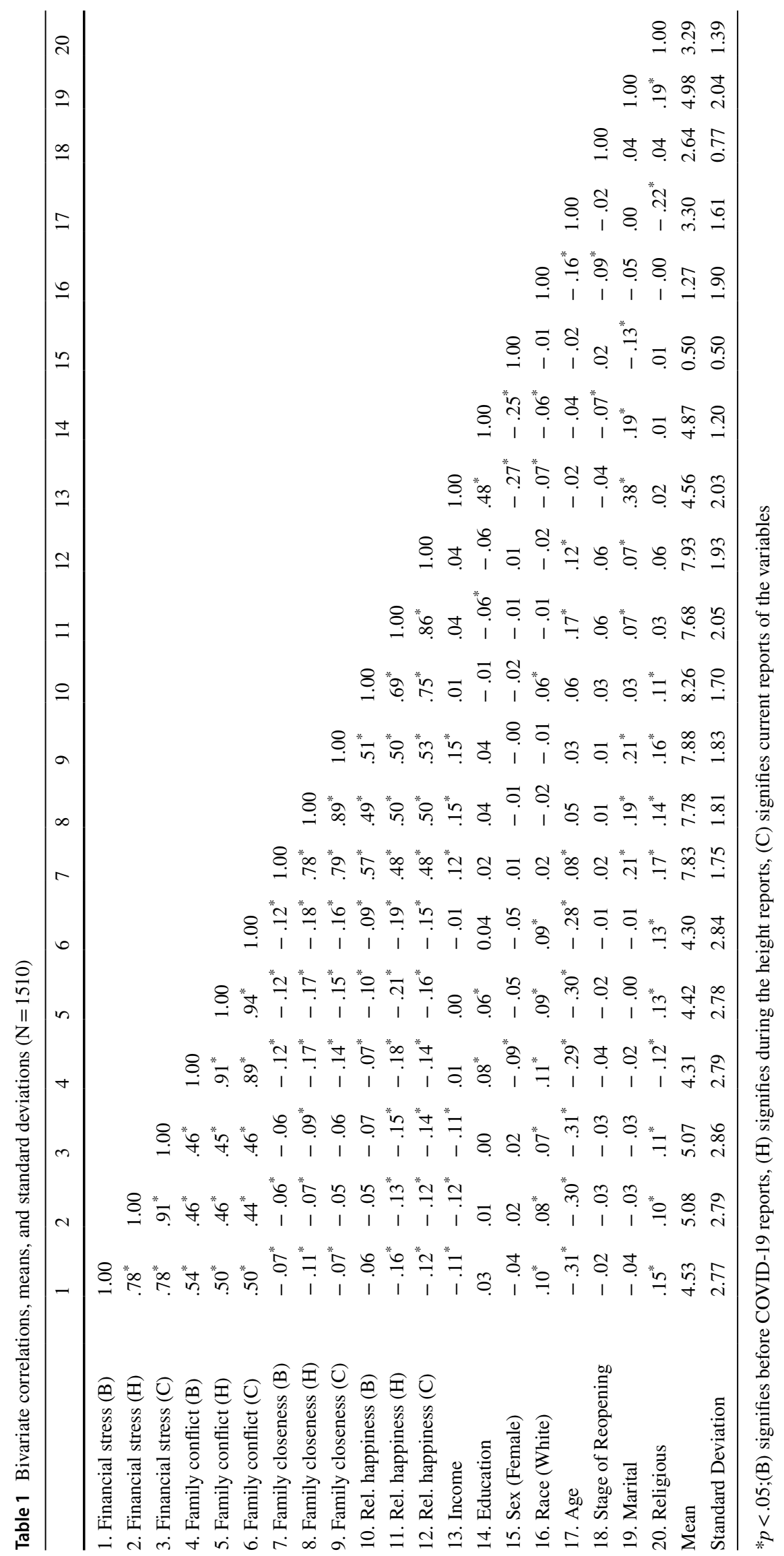


Table 2 OLS regression results: changes in financial stress and relational wellbeing

\begin{tabular}{|c|c|c|c|}
\hline & $\begin{array}{l}\text { Relational conflict } \\
(N=1,510)\end{array}$ & $\begin{array}{l}\text { Emotional close- } \\
\text { ness }(N=1,510)\end{array}$ & $\begin{array}{l}\text { Relationship } \\
\text { happiness } \\
(N=1,062)\end{array}$ \\
\hline \multicolumn{4}{|l|}{ Change in Financial Stress (Maintained) } \\
\hline Decreased & $\begin{array}{l}-0.39^{* * *} \\
(0.09)\end{array}$ & $\begin{array}{l}-0.43^{* * *} \\
(0.09)\end{array}$ & $\begin{array}{l}-0.53^{* * *} \\
(0.13)\end{array}$ \\
\hline Increased & $\begin{array}{l}0.17^{*} \\
(0.07)\end{array}$ & $\begin{array}{l}0.05 \\
(0.07)\end{array}$ & $\begin{array}{l}-0.25^{*} \\
(0.10)\end{array}$ \\
\hline Household Income & $\begin{array}{l}0.00 \\
(0.02)\end{array}$ & $\begin{array}{l}0.06^{* *} \\
(0.02)\end{array}$ & $\begin{array}{l}0.07^{* *} \\
(0.03)\end{array}$ \\
\hline Education & $\begin{array}{l}-0.03 \\
(0.03)\end{array}$ & $\begin{array}{l}-0.01 \\
(0.03)\end{array}$ & $\begin{array}{l}-0.09^{*} \\
(0.05)\end{array}$ \\
\hline Sex (Female) & $\begin{array}{l}0.12 \\
(0.07)\end{array}$ & $\begin{array}{l}-0.05 \\
(0.06)\end{array}$ & $\begin{array}{l}0.04 \\
(0.10)\end{array}$ \\
\hline \multicolumn{4}{|l|}{ Race (White) } \\
\hline Other & $\begin{array}{l}-0.13 \\
(0.19)\end{array}$ & $\begin{array}{l}0.25 \\
(0.18)\end{array}$ & $\begin{array}{l}0.32 \\
(0.28)\end{array}$ \\
\hline Asian & $\begin{array}{l}-0.12 \\
(0.09)\end{array}$ & $\begin{array}{l}-0.10 \\
(0.08)\end{array}$ & $\begin{array}{l}-0.26^{*} \\
(0.12)\end{array}$ \\
\hline Black & $\begin{array}{l}-0.15 \\
(0.11)\end{array}$ & $\begin{array}{l}-0.11 \\
(0.11)\end{array}$ & $\begin{array}{l}-0.01 \\
(0.19)\end{array}$ \\
\hline Hispanic & $\begin{array}{l}-0.17 \\
(0.11)\end{array}$ & $\begin{array}{l}-0.20 \\
(0.11)\end{array}$ & $\begin{array}{l}-0.28 \\
(0.17)\end{array}$ \\
\hline Age & $\begin{array}{l}-0.07^{* * * *} \\
(0.02)\end{array}$ & $\begin{array}{l}-0.04^{*} \\
(0.02)\end{array}$ & $\begin{array}{l}0.12^{* * *} \\
(0.03)\end{array}$ \\
\hline \multicolumn{4}{|l|}{ Stage of Reopening (Red) } \\
\hline Orange & $\begin{array}{l}0.05 \\
(0.13)\end{array}$ & $\begin{array}{l}-0.03 \\
(0.13)\end{array}$ & $\begin{array}{l}0.25 \\
(0.19)\end{array}$ \\
\hline Yellow & $\begin{array}{l}0.04 \\
(0.13)\end{array}$ & $\begin{array}{l}-0.01 \\
(0.13)\end{array}$ & $\begin{array}{l}0.43^{*} \\
(0.18)\end{array}$ \\
\hline Green & $\begin{array}{l}0.17 \\
(0.15)\end{array}$ & $\begin{array}{l}-0.08 \\
(0.15)\end{array}$ & $\begin{array}{l}0.18 \\
(0.21)\end{array}$ \\
\hline Religiosity & $\begin{array}{l}0.03 \\
(0.02)\end{array}$ & $\begin{array}{l}0.02 \\
(0.02)\end{array}$ & $\begin{array}{l}-0.01 \\
(0.03)\end{array}$ \\
\hline Marital Status (Married) & $\begin{array}{l}0.02 \\
(0.02)\end{array}$ & $\begin{array}{l}-0.00 \\
(0.02)\end{array}$ & $\begin{array}{l}0.08 \\
(0.10)\end{array}$ \\
\hline Before-COVID-19 Reports of Outcome & $\begin{array}{l}0.91^{* * *} \\
(0.01)\end{array}$ & $\begin{array}{l}0.79^{* * * *} \\
(0.02)\end{array}$ & $\begin{array}{l}0.82^{* * *} \\
(0.03)\end{array}$ \\
\hline Constant & $\begin{array}{l}0.71^{* * *} \\
(0.25)\end{array}$ & $\begin{array}{l}1.60^{* * * *} \\
(0.25)\end{array}$ & $\begin{array}{l}0.58 \\
(0.41)\end{array}$ \\
\hline Observations & 1442 & 1442 & 1062 \\
\hline$R^{2}$ & 0.827 & 0.614 & 0.514 \\
\hline
\end{tabular}

For categorical variables, the comparison group is designated in parentheses. The reported coefficients are standardized. Standard errors are in parentheses

${ }^{*} p<0.05, * * p<0.01, * * * p<0.001$ reported maintaining their before levels of financial stress, and $35.8 \%$ reported increased financial stress. ${ }^{3}$

\footnotetext{
${ }^{3}$ Note that we do not claim that these percentages reflect the experiences of all Americans, as our sample was disproportionately wealthy and well-educated, groups that tended to fare relatively well during the pandemic compared to other groups.
}

Regression analyses looking at differences in relational wellbeing between these three groups, where those who maintained their levels of financial stress were used as the comparison group, can be found in Table 2. Compared to those who maintained their before levels of financial stress, decreasing in financial stress was associated with decreased 
relational conflict ( $\beta=-0.39 ; p<0.001$; bonadaptation), and increasing in financial stress was associated with increased relational conflict $(\beta=0.17 ; p=0.015$; maladaptation), supporting Hypotheses 1 and 2. However, contrary to our hypotheses, when looking at emotional closeness and relationship happiness, we saw that those who decreased in financial stress also decreased in emotional closeness ( $\beta=-0.43 ; p<0.001$; maladaptation) and relationship happiness $(\beta=-0.53 ; p<0.001$; maladaptation) compared to those who maintained their before levels of financial stress. Those who increased in financial stress were not significantly different from those who maintained levels of financial stress in their reports of familial emotional closeness ( $\beta=0.05 ; p=0.500$ ) but were significantly more likely to report decreased happiness in their romantic relationships ( $\beta=-0.25 ; p=0.014$; maladaptation). When looking at additional between-group comparisons of the increased and decreased groups, those who increased in financial stress were significantly more likely to report increased relational conflict ( $\beta=0.56 ; p<0.001$; maladaptation) but were also significantly more likely to report increased emotional closeness ( $\beta=0.47 ; p<0.001$; bonadaptation) and increased happiness in romantic relationships $(\beta=0.29 ; p=0.034$; bonadaptation), showing only partial support for our hypotheses 1 and 2 . See Table 2 for a summary of the significant control variables.

\section{Qualitative Results}

Following the quantitative question regarding how much financial stress they felt, we asked the following, optional open-ended questions: "Do you have any related thoughts or experiences regarding how financial stress related to COVID-19 impacted you or your family? What helped you cope with this financial stress?" In response to these questions, we got insightful responses regarding both what exacerbated (i.e., increased objective financial stressors or perceived financial stress) and what alleviated (i.e., helped participants cope with) financial stress. Here we briefly describe eight factors that exacerbated participants' financial stress and eight factors that alleviated participants' financial stress. In line with recommendations for qualitative research, we used direct quotes from our participants to illustrate each of these themes (Marks, 2015). Frequencies of how often each of the alleviating and exacerbating factors were identified by coders are included in Table 3 .

\section{Exacerbating Influences of COVID-19 on Financial Stress}

Over 35\% percent of the sample reported that their financial stress increased from before COVID-19. These qualitative
Table 3 Numeric content analysis of qualitative results $(\mathrm{N}=648)$

\begin{tabular}{lll}
\hline Exacerbating influences & & \\
\hline & Count & Percentage \\
\hline Worry About Future Economic Situation & 85 & $24.4 \%$ \\
Reduced Hours or Household Income & 84 & $24.1 \%$ \\
Unemployment & 71 & $20.3 \%$ \\
Higher Bills and Costs & 51 & $14.6 \%$ \\
Struggling to Cope & 48 & $13.7 \%$ \\
Relational Stress, Challenges, or Worry & 47 & $13.5 \%$ \\
Retirement or Investments Were Negatively & 44 & $12.6 \%$ \\
$\quad$ Impacted & & \\
Did Not Receive Government Benefits & 28 & $8.0 \%$ \\
Total & $349 *$ & $100 \%$ \\
Alleviating Influences & & \\
Still Having Income & 114 & $27.7 \%$ \\
Current Sound Financial Practices & 83 & $20.2 \%$ \\
Past Sound Financial Practices & 79 & $19.2 \%$ \\
Mental Reframing and Staying Positive & 79 & $19.2 \%$ \\
Government Benefits & 74 & $18.0 \%$ \\
Family & 59 & $14.4 \%$ \\
Religious or Spiritual Practices or Beliefs & 57 & $13.9 \%$ \\
Reduced Costs or Expenses & 55 & $13.4 \%$ \\
Total & $411 *$ & $100 \%$ \\
& & \\
& &
\end{tabular}

Percentages were calculated by dividing the number of accounts in each theme by the total number of exacerbating or alleviating influences. The total numbers represent the total number of accounts coded as either an exacerbating or an alleviating influence. Some accounts included multiple exacerbating or alleviating influences. As such, the sum of the individual counts exceeds the total and the sum of the percentages exceed $100 \%$. Several other themes that were identified and coded for, but not included due to low prevalence. Among exacerbating influences these included being required to help others financially (viewed negatively or as a sacrifice), decreased work satisfaction, and general stress about the virus while alleviating influences these included the ability to help others (viewed as something positive), distractions or avoidance, and receiving financial help from others

findings provide insight into specific factors and influences that led to increased financial stress for individuals and families. The top eight most common exacerbating factors will be briefly reviewed here, moving from the most-commonlystated factors to the least-commonly-stated factors.

\section{Negative Meaning: Worry About Future Economic Situation}

With 85 accounts identified, the most common exacerbating influence mentioned was worry about the future economic situation. The most common specific worry identified in this theme was related to job security. One participant stated, "My stress comes from not knowing about my work stability." Specific concerns over the stock-market and investments were also identified: "I' $m$ more concerned with my 
long-term investments knowing that we have an election four months away and what could happen then." Other concerns were focused on more general worry and apprehension of future economic situation as seen in the following account: "Most of my financial stress due to coronavirus does not have to do with my current situation, but rather stress due to uncertainty for the future and those financial goals." Another participant similarly stated, "The uncertainty is the most difficult thing to deal with when it comes to money."

\section{Reduced Capabilities: Reduced Hours or Household Income}

The next most common exacerbating influence (84 accounts) identified was related to reduced household income, primarily as a result of reduced hours or pay cuts. There were varying degrees of stress associated with reduced income. The following account is one example of lower levels of stress associated with a pay cut:

My overtime got cut for about a month and a half. I did miss it, but not enough that it affected my life greatly. I was still able to pay all my bills and keep going with life until my overtime picked back up.

An example of a more stressful experience is provided by a newly-married individual, who said, "I am a graduate student and already get paid very little, so having my husband's hours cut during COVID created a significant source of financial stress to us, especially as newlyweds." For some families, multiple individuals experienced pay cuts simultaneously:

[Our] primary income had a decrease (but [I] stayed employed working from home), [our] secondary income was furloughed and employed only 1 day per week from 5 days full time. [Our two] children who work part time were both furloughed at different times - one is back to work now and the other was working to support himself at university but is now furloughed until late September without work living at home until Fall term starts up again.

\section{Reduced Capabilities: Unemployment}

While the previous section focused on cuts to income, this theme (71 accounts) deals with a complete job loss. One participant said, "[My] spouse lost his job and has been unable to find work since. The only thing that helps is our savings and unemployment." Another participant described losing their job and being able to find another part-time job, but still wanting more stable work:

I lost my job so I was without a job for a little over 2 months and had a very difficult time finding a new job, it has been so hard to find a permanent job, I have been trying to find a stable job for over 4 years. I officially don't think that I will ever get a permanent job due to the current crisis we are in.

\section{Increased Demands: Higher Bills and Costs}

While some participants reported that COVID-19 helped reduce their expenses, others reported (51 accounts) that they saw an increase in their expenses following COVID19 related closures. The most commonly reported increased expense was food and groceries. One participant stated, "Financial stress related to COVID-19 impacted me and my family because of increased spending on necessities such as food and medicine as well as household cleaning supplies." Other participants described how certain expenses increased while others decreased. One participant described this, saying, "I am spending more on groceries and such but less on movies and such, so it balances out."

\section{Increased Demands: Relational Stress and Demands}

Accounts from 47 participants commented on how financial stress had a negative influence on their relationship or increased their relational demands. One participant succinctly stated, "Increased stress puts strains on any relationship." Others talked about the challenges of balancing their work and new homeschooling responsibilities. One parent said, "Homeschooling the children has been challenging while I have been working at home," while another conveyed that they "Had to quit a job because I needed to homeschool." Participants also discussed how they needed to help-out other family members financially, sometimes when they themselves were struggling. One participant said, "Our financial stress was due to financially helping other family members who lost their jobs."

\section{Reduced Capabilities: Retirement Funds or Investments were Negatively Impacted}

Concerns and losses in investments or retirement funds were also a common exacerbating influence (44 accounts). One participant said, "Stress from the fluctuations in the stock market affected our family the most. Being patient and hopeful that the market would go back." Another individual stated, "[I have] more financial stress related to stock and bond markets." For many participants, these concerns were tied to their future wellbeing, while for some, the fluctuations in the stock market had more immediate impacts, as seen in the following account: "The stock market losses affected my funds available to me and made me cut down on some things that were necessary." However, it is important to note that now nearly a year after this survey was initially distributed, that many of these funds may have recovered. 


\section{Reduced Capabilities: Did Not Receive Government Benefits}

We identified 28 accounts related to not receiving government benefits or money that participants were expecting to receive. Most of the accounts in this section dealt with not qualifying for or receiving unemployment benefits after a job loss or reduced hours. One participant recounted, "I tried to apply for pandemic assistance, and it was not a good process. I wasn't eligible and was told I could apply for regular unemployment since my hours were reduced. I did not qualify for that either." Others did not receive or were unable to access their stimulus package. One participant said, "My exhusband received my stimulus package. With the IRS being closed I have not been able to get it or talk to anyone about it." Other issues that were mentioned included delays of tax returns, as seen in the following account: "The pandemic has continued to delay a substantial income tax refund from the Internal Revenue Service, which has caused mild anxiety."

\section{Reduced Capabilities: Struggling to Cope}

Although this final theme, comprised of 48 accounts, is not related to a specific exacerbating influence, it is important to highlight that some participants reported that they were struggling or unable to cope successfully with the financial stress they were experiencing. Many of these reports included experiencing several of the themes identified as exacerbating influences together, and not feeling unable to do anything about it. One participant said, "Nothing. Property taxes are astronomical. Price of food, groceries, necessities, [and] utilities is astronomical. And I fear that everything is only going up and make it truly unaffordable." Another participant stated, "Missing out on some income. Not coping well with the stress," while another participant surmised, "To be honest, [it's] a hard time for all of us."

\section{Exacerbating Influences of COVID-19: Summary}

We identified eight factors that appeared to exacerbate financial stress related to COVID-19, most of which were related to decreased capabilities/resources. These included reduced hours or household income, unemployment, negative impacts to retirement funds or investments, not receiving expected government benefits, and that they were struggling to cope with the financial stress overall. Looking at increased demands, some participants reported that their bills and expenses had increased, and some participants also reported increased relational stress and demands related to their financial stress stemming from COVID-19. We only identified one explicit negative meaning (i.e., participants' worry about the future economic situation); however, this was the most commonly occurring exacerbating influence identified in our data.

\section{Alleviating Influences or Coping Mechanisms Related to COVID-19 and Financial Stress}

Over $15 \%$ of the sample reported that their levels of financial stress actually decreased along with the COVID-19 shutdowns, and nearly $50 \%$ of the sample reported that their levels of financial stress had not changed. These qualitative findings help illuminate these quantitative trends and provide insight into how individuals and families coped with financial stress related to COVID-19. The eight most common alleviating factors will be briefly reviewed here, moving from the most-commonly-stated factors to the leastcommonly-stated factors.

\section{Capabilities: Still Having Income}

With 114 accounts, the most commonly mentioned alleviating influence was that participants still had an income. Many of these accounts focused on gratitude for job security and maintaining their income while others had lost their income due to COVID-19. One person simply said, "We were fortunate to maintain my husband's employment. I don't work." For some participants, they expressed that while a family member had lost a job or their hours had been reduced, they still had some income, for which they were grateful, as seen in the following account: "[My] husband was furloughed from his job... STILL no [money] from [Unemployment]. Thankfully I am still gainfully employed, or we'd be in serious trouble."

\section{Capabilities: Current Sound Financial Practices}

The next most common alleviating factor ( 83 accounts) related to participants positive financial behaviors that they either began or were using when the pandemic hit. The most common practice mentioned was reduced spending. One participant said, "My family reduced unnecessary cost[s] for this so much." Other common practices included sticking to a budget, striving to save money, seeking additional work or income (e.g., gigs, jobs, more work hours, online surveys, donating plasma), maintaining or using investment strategies, relying on home-sourced food (e.g., food storage, gardens), paying off debt, "couponing," and being a good employee. A few participants also talked about onetime actions they took, such as visiting a financial advisor, sitting down and reassessing their financial situation, and using their stimulus check.

\section{Capabilities: Past Sound Financial Practices}

While the previous theme focused on practices that people were currently doing to help cope with financial stress, the 79 identified accounts in this theme dealt with past financial 
behaviors that brought individuals and families reduced stress or peace of mind amidst increased financial uncertainty. The most common behavior identified in this theme was having savings or an emergency fund. One participant stated, "We had been diligent about saving money before the coronavirus so even though our investments tumbled we had money saved over as backup in case we needed it so there was minimal financial stress." The other most common behavior identified in this theme was not having debt or having already made good progress getting out of debt before COVID-19 hit. This is described by one participant as follows: "We are good financial managers, never spend more than we can pay off immediately," while another participant said, "We were already in the process of getting out of debt before COVID-19."

\section{Positive Meaning: Mental Reframing and Staying Positive}

Another common alleviating influence (79 accounts) related to staying positive or focusing on the good in relation to any financial difficulties they were facing. This was often expressed by focusing on what they were grateful for, as expressed in the following account: "Just trying to stay positive and look at the positives that we were all healthy." Another common theme identified in this section was focusing on what was gained rather than what was lost. One participant described how this by saying, "COVID-19 has made life a little more simple because there wasn't as many opportunities to go out and spend money for luxury items." Other mental reframing techniques included not trying to control the uncontrollable, remaining hopeful, and acknowledging that their financial difficulties were much smaller than the challenges many others were currently facing.

\section{Capabilities: Government Benefits}

Seventy-four participants cited financial benefits from the government as important alleviating factors. Almost all of the accounts identified in this theme related to either receiving the stimulus check or receiving unemployment. For both those who maintained regular income and those who lost income, stimulus checks were viewed as an important benefit or financial relief. One person said, "We didn't have any financial stress because our income didn't change and the stimulus checks were a great bonus for us to improve our debt level." Another participant stated, "Unemployment and the stimulus helped to keep our family afloat." A few participants who reported job loss even stated that they were now making more on unemployment than they were making at their previous job.

\section{Capabilities: Family}

We identified 59 accounts where participants reported that their family helped them cope with their financial stress. Most of these accounts focused on how just spending time with their family helped them deal with the stress. One participant stated, "My wife [has] helped me cope with my stress. She is my anchor." Another participant said, "Time away from work helped us spend more time as a family. Faith, flexibility, counseling as a family, communication helped us cope." While most of the accounts in this section were similar to these two, a few accounts focused on directly receiving financial aid from family members to make ends meet.

\section{Capabilities: Religious/Spiritual Practices and Beliefs}

For 57 of our participants, religious/spiritual beliefs and practices ${ }^{4}$ reportedly helped them cope with COVID-19-related financial stress. The most common of these beliefs and practices was prayer. This is expressed in the following account: "I have always dealt with stress through prayer, and I continue to use this method to deal with it." Other common responses included meditation, a general belief in or relationship with God, working or getting advice from religious leaders, and relying on their religious community for support.

\section{Reduced Demands: Reduced Costs or Expenses}

Another alleviating influence identified in 55 accounts was reduced individual or family expenses as a result of COVID-19. Many of these accounts described how expenses were reduced because individuals were no longer able to participate in activities they normally would have. This included not having to spend money on gas to commute or attend other activities, eating out, traveling, and so forth. One participant stated, "No more need to pay for a nanny, drive, vacation, etc. This pandemic has been a godsend to us financially."

\section{Alleviating Influences of COVID-19: Summary}

The most common alleviating influence we identified related to still having an income, something they appreciated and

\footnotetext{
$\overline{4}$ To address other research questions which are not part of this specific study but which are important to the overarching study, religious people from various religious traditions were oversampled, which likely contributed to this finding. However, it is important to note that this question appeared in the survey before any questions focused on religious or spiritual beliefs and practices, and, as such, the survey itself did not prompt these responses.
} 
valued more than before the pandemic as they saw many others lose their income. Many participants highlighted their past financial choices that could now act as a financial security net while others emphasized the current financial practices they were employing to improve their financial situation. Participants also reported their family and their religious or spiritual beliefs as resources that helped them cope with their financial stress. For decreased demands, some participants reported decreased expenses as a result of COVID-19. Finally, many participants reported how intentionally changing their meanings by staying positive or reframing their challenges helped reduce their financial stress. As with exacerbating influences, participants often reported some of these alleviating influences together.

\section{Discussion}

We looked at the influence of COVID-19-induced changes in financial stress on family wellbeing. Interestingly, while approximately $16 \%$ of participants reported decreased financial stress and just over 35\% reported increased financial stress, nearly half of our sample reported no changes in their financial stress. In terms of the FAAR model (Patterson, 1988), we viewed COVID-19 as a stressor that impelled most families into crisis and the adaptation phase of the model. We viewed financial stress as a demand, and hence increases in financial stress as an increase in demands and decreases in financial stress as a decrease in demands; we viewed three measures of relational wellbeing as measures of adaptation, with improved relational outcomes suggesting bonadaptation and poorer relational outcomes suggesting maladaptation. Following this logic, we hypothesized that increases in financial stress would be associated with decreases in relational wellbeing (H1) while decreases in financial stress would be associated with improved relational wellbeing (H2). These hypotheses were only partially confirmed across the three measures of relational wellbeing. This pattern was confirmed for relational conflict, where increased financial stress was associated with increased conflict and decreased financial stress was associated with decreased conflict. However, when we looked at emotional closeness and couple relationship happiness, the associations we observed were in the opposite direction of what we had hypothesized. Specifically, those who decreased in financial stress also reported decreased emotional closeness and relationship happiness compared to those who maintained their before COVID-19 levels of financial stress.

Despite the incongruence between our hypotheses and findings, these findings still fit within the FAAR model (Patterson, 1988) and previous literature (Dew et al., 2018; LeBaron et al., 2020). The FAAR model suggests that stressors and demands that disrupt the family system can lead to either maladaptation or bonadaptation, depending largely on resources and capabilities (e.g., financial, relational, social resources and capabilities) available to the family system (Patterson, 1988). Previous literature has suggested that as long as couples have sufficient relational resources (i.e., relationship maintenance behaviors) and financial resources (i.e., financial support from friends/family) to cope with their financial stressors, these stressors can provide opportunities for couples and families to work together and can strengthen elements of their relationships (Dew et al., 2018; LeBaron et al., 2020). Our results support these previous findings that financial stress has the potential to increase both negative and positive processes in relationships. Our qualitative findings provide context as to what circumstances (i.e., what demands, capabilities, and meanings) might foster maladaptation or bonadaptation, both of which will be discussed briefly below.

\section{Potential Pathways for Maladaptation and Bonadaption}

According to the FAAR model (Patterson, 1988), maladaptation tends to occur when there are increased demands, reduced capabilities, and negative meanings. Most of the factors we identified were related to decreased capabilities/resources. Specifically, two of the most commonly mentioned exacerbating influences were reduced hours or household income and unemployment. Other decreased capabilities included were that their retirement funds or investments were negatively impacted, ${ }^{5}$ that they did not receive expected government benefits, and that they were struggling to cope with the financial stress overall. Previous research has demonstrated the potential harms of these types of economic pressure on wellbeing and relationships (Friedline et al., 2020).

Consistent with previous research (e.g., Archuleta et al., 2011; Stewart et al., 2017), some participants also reported increased relational stress and demands related to their financial stress stemming from COVID-19. How households experience and cope with decreased capabilities and increased demands is associated with the meanings they place on these demands and capabilities (Patterson, 1988). Although we only identified one explicit negative meaning (i.e., participants' worry about the future economic situation), this was the most commonly occurring exacerbating influence identified in our data. Many participants reported that more than one of these exacerbating influences occurred concurrently. Consistent with the FAAR model (Patterson, 1988) and observed in our data, when participants reported

\footnotetext{
5 We note that now, nearly a year after the survey was completed, it is possible that many of these funds have recovered.
} 
multiple of these exacerbating influences together, their qualitative accounts often appeared to report greater distress in regard to their financial situation as well; however, while we note this observation, we acknowledge that we did not have a succinct way to measure this, and thus, we present this observation as something for future research to investigate.

On the other hand, bonadaptation tends to occur when there are reduced demands, enough or increased capabilities, and positive meanings (Patterson, 1988). Despite how COVID-19 reduced the financial capabilities of many households, it reportedly increased the capabilities of many as well. In many instances, the capability itself did not change; rather, the meaning placed on the capability changed in a way that helped participants cope with financial stress. Specifically, the most commonly identified alleviating influence was that they still had an income, something they reportedly appreciated and valued more than they did before the pandemic, as they saw many others lose their income. Relatedly, and in line with Prime et al.'s (2020) focus on the importance of preexisting strengths or vulnerabilities in relation to how families weather this pandemic, many participants also highlighted their past financial choices and practices that could now act as a financial security net during the pandemic. Others emphasized the current financial practices they were employing to improve their financial situation and give them peace of mind.

Beyond financial resources and capabilities, participants also reported their family and their religious or spiritual beliefs and practices as resources that helped them cope with their financial stress. Previous literature has shown that while religion can help reduce financial stress (LeBaron et al., 2019), it can also increase the harmful effects of financial stress on wellbeing, especially if the financial crisis is viewed as a punishment from God (Stein et al., 2013). While we did not identify participants viewing the economic situation as a punishment from God, future research should continue investigating the complex connections between religion, financial stress, and wellbeing. We identified only one decreased demand in our data: despite some participants reporting increased bills as an exacerbating influence, others reported that their expenses decreased as a result of COVID19 and was thus an alleviating influence. Despite the positive and negative changes in demands and capabilities discussed thus far, and while meanings are woven throughout how participants viewed their capabilities, nearly $20 \%$ of the alleviating accounts identified were specifically about how intentionally changing their meanings by staying positive or reframing the challenges they were facing help reduce participants' financial stress. Again, as with exacerbating influences, participants often reported some of these alleviating influences together.

\section{Implications for Clinicians, Financial Professionals, and Educators}

The findings of this study suggest that changes in financial stress due to COVID-19 can have both positive and negative impacts on family relationships. More specifically, families who experienced an increase in financial stress were more likely to experience more conflict but also reported more emotional closeness and relationship happiness than those who decreased. Similarly, families who experienced a decrease in financial stress were likely to experience less conflict but also reported less emotional closeness and relationship happiness. Although the COVID-19 pandemic is a unique stressor event, these findings align with other research supporting the FAAR model (Patterson, 1988) and demonstrating how families cope with demands to achieve bonadaptation (Dew et al., 2018; LeBaron et al., 2019, 2020); thus, it is possible that these findings (e.g., pathways for bonadaptation) might be applied for individuals and families experiencing other stressor events and demands beyond COVID-19 related financial stress. These findings have implications for counselors, therapists (including financial therapists and marriage and family therapists), financial professionals (including financial counselors and financial planners), and educators (including financial educators and family life educators).

First, as individuals experience stress related to COVID19 , our findings suggested that financial stress can exacerbate relational conflicts. One way to approach this problem is by targeting financial management skills, as supported by our findings that past and current sound financial practices were reported as alleviating influences. Clinicians and educators can refer individuals to financial professionals (e.g., financial therapists, financial counselors, and financial planners) who can provide information on what money management strategies and financial resources can help them improve their financial situation and reduce their financial stress. Programs or interventions developed by these professionals may be particularly effective for couples when focused on working with both partners together to improve their financial knowledge and communication skills (Britt-Lutter et al., 2019; Falconier, 2015). Specifically, our qualitative findings showed that financial stress increased relational stress for some, while others reported that their family relationships helped them better cope with the financial stress they were facing. While we cannot determine why relationships were an exacerbating influence for some and an alleviating influence for others, previous research suggests that communication may play an important role in this process and may decrease feelings of stress that come from ambiguity (Dew et al., 2012; Grobbelaar \& Alsemgeest, 2016; LeBaron et al., 2018). Additionally, as financial practitioners help their clients improve both their 
financial knowledge and communication as well as their general relationship communication, the negative effects of financial stress on relationships will likely decrease (Kelley et al., 2018; Olson \& Rick, 2018).

As research suggests that many Americans lack the financial literacy to navigate financial crises (Lusardi et al., 2020), financial educators and financial professionals could also help people develop financial knowledge and capabilities in order to be prepared for future unexpected financial crises. In addition to teaching students or clients how to deal with day-to-day financial matters (e.g., budgeting, credit cards management, tracking expenses), financial educators and professionals could also help them be prepared for financial shock due to economic recession. In their financial education programs, the importance of emergency savings should be stressed by teaching how to set aside money for an emergency fund. Such financial management tactics and strategies (i.e., setting up an emergency fund) should be learned, motivated, and further developed through many different channels of financial education such as homes, schools, colleges, and workplaces (LeBaron \& Kelley, 2020).

Finally, clinicians can help individuals and families experiencing financial stress to develop positive meanings about their situation. Individuals and families can use difficult times, even crises, as an opportunity for learning and growth. Indeed, by definition, bonadaptation suggests that growth occurred which may not have occurred without a catalyst crisis (LeBaron et al., 2019, 2020). In the current study we found that mental reframing and staying positive, including focusing on gratitude, helped financially stressed individuals cope and appeared to facilitate relational bonadaptation. Similarly, other studies have found that positive reframing and gratitude can help individuals have a sense of coherence (Lambert et al., 2009) and fewer depressive symptoms (Lambert et al., 2012).

\section{Limitations and Directions for Future Research}

Despite the strengths of this study, including our mixed methods design and large, diverse sample, there were several important limitations. First, regarding our quantitative analysis, we relied on single-item measures. Future research should include validated scales to measure constructs of family and relational wellbeing and changes in financial stress. Further, despite the racial and ethnic diversity of our sample, on average, the sample was highly educated and highly religious, and the majority of the sample was married. ${ }^{6}$ The relatively high SES demographics of this sample

\footnotetext{
${ }^{6}$ We note that the disproportionate number of religious and married individuals stems in part from intentionally oversampling these groups based on overarching goals of conducting this survey to better understand home-centered practices (across religious groups) and relational wellbeing during the pandemic.
}

may have contributed to the fact that nearly half of the sample reported no changes in financial stress at the time of the survey, as it is the financially vulnerable that appear to most impacted by the pandemic (Parker et al., 2020). Further research is needed on this group that reported no changes in financial stress during the first few months of the pandemic.

As our sample is not nationally representative, our findings cannot be generalized to the general population; future research on this topic should ideally employ a nationallyrepresentative sample and examine these associations among specific minority groups that have been disproportionately impacted by the pandemic. Finally, while our findings supported previous research that has shown that financial stress can both harm relationships as well as create opportunities to strengthen relationships (Dew et al., 2018; LeBaron et al., 2020), more research is needed regarding the circumstances and individual/relational characteristics that lead to financial stress being an opportunity for relational growth rather than relational harm.

Ideally, qualitative and quantitative research should build from and inform each other (Marks, 2015). With our qualitative data, we can only explore potential pathways to maladaptation and bonadaptation. Research that quantifies the qualitative themes we have identified here can help test possible associations between these factors and relational wellbeing. Specifically, future research can test these pathways by including the capabilities, meanings, and demands as moderators and mediators to test which of these might act as protective factors against the deleterious effects of financial stress on relationships.

\section{Conclusion}

This study highlights the dynamic influences of COVID19 on financial and relational wellbeing and demonstrated that the impact of changes in financial stress on relational wellbeing is multifaceted. We found evidence for potential pathways to relational bonadaptation and potential pathways for relational maladaptation following changes in financial stress. Our qualitative analysis suggested that COVID-19 appeared to most often exacerbate financial stress by diminishing resources or capabilities available to individuals and families, but changes in households' meanings, or how they viewed their capabilities, may help alleviate some financial stress. Associations between financial stress and family relationships during COVID-19 are complex and warrant further research.

Funding No funding was received for this article.

Data Availability Data is not currently available to the public. 


\section{Declarations}

Conflict of interest We have no known conflict of interest to disclose.

Ethical Approval We obtained Institutional Review Board approval and informed consent prior to the collection of this data.

Consent to Participate This article is written in compliance with accepted.

Consent for Publication The authors of this article consent to its publication is the Journal of Family and Economic Issues.

\section{References}

APA. (2015). Stress in America: Paying with our Health. American Psychological Association. http://www.apa.org/news/press/relea ses/stress/2014/stress-report.pdf

APA. (2019). Stress in America 2019. American Psychological Association. https://www.apa.org/news/press/releases/stress/2019/ stress-america-2019.pdf

Archuleta, K. L., Britt, S. L., Tonn, T. J., \& Grable, J. E. (2011). Financial satisfaction and financial stressors in marital satisfaction. Psychological Reports, 108(2), 563-576. https://doi.org/10.2466/07. 21.PR0.108.2.563-576

Albulescu, C. T. (2020). COVID-19 and the United States financial markets' volatility. Finance Research Letters, 10(1), 699. https:// doi.org/10.1016/j.frl.2020.101699

Ashraf, B. N. (2020). Stock markets' reaction to COVID-19: Cases or fatalities? Research in International Business and Finance, 10(1), 249. https://doi.org/10.1016/j.ribaf.2020.101249

Aytaç, I. A., \& Rankin, B. H. (2009). Economic crisis and marital problems in Turkey: Testing the family stress model. Journal of Marriage and Family, 71(3), 756-767. https://doi.org/10.1111/j. 1741-3737.2009.00631.x

Bradley, C., \& Stumpner, P. (2021, March 10). The impact of COVID19 on capital markets, one year in. McKinsey \& Company. https:// www.mckinsey.com/business-functions/strategy-and-corporatefinance/our-insights/the-impact-of-covid-19-on-capital-marke ts-one-year-in\#

Britt-Lutter, S., Haselwood, C., \& Koochel, E. (2019). Love and money: Reducing stress and improving couple happiness. Marriage \& Family Review, 55(4), 330-345.

Brown, S. M., Doom, J., Watamura, S. E., Lechuga-Pena, S., \& Koppels, T. (2020). Stress and parenting during the global COVID19 pandemic. Child Abuse \& Neglect. https://doi.org/10.1016/j. chiabu.2020.104699

CDC. (2020, July 1). Coping with Stress. Centers for Disease Control and Prevention. https://www.cdc.gov/coronavirus/2019-ncov/ daily-life-coping/managing-stress-anxiety.html

Conger, R. D., Elder, G. J., Lorenz, F. O., Conger, K. J., Simons, R. L., Whitbeck, L. B., \& Melby, J. N. (1990). Linking economic hardship to marital quality and instability. Journal of Marriage and the Family, 52(3), 643-656. https://doi.org/10.2307/352931

Conger, K. J., Rueter, M. A., \& Conger, R. D. (2000). The role of economic pressure in the lives of parents and their adolescents: The Family Stress Model. In L. J. Crockett \& R. K. Silbereisen (Eds.), Negotiating adolescence in times of social change (pp. 201-223). Cambridge University Press.

Croce, B. (2020, October 14). More Americans hurting financially amid pandemic - surveys. Pensions and Investments. https://www. pionline.com/defined-contribution/more-americans-hurting-finan cially-amid-pandemic-surveys
Dew, J. (2020). Ten years of marriage and cohabitation research in the Journal of Family and Economic Issues. Journal of Family and Economic Issues, 2020, 1-10.

Dew, J. (2011). The association between consumer debt and the likelihood of divorce. Journal of Family and Economic Issues, 32(4), 554-565. https://doi.org/10.1007/s10834-011-9274-z

Dew, J., Britt, S., \& Huston, S. (2012). Examining the relationship between financial issues and divorce. Family Relations, 61(4), 615-628. https://doi.org/10.1111/j.1741-3729.2012.00715.x

Dew, J. P., LeBaron, A. B., \& Allsop, D. B. (2018). Can stress build relationships? Predictors of increased marital commitment resulting from the 2007-2009 recession. Journal of Family and Economic Issues. https://doi.org/10.1007/s10834-018-9566-7

Dew, J. P., \& Xiao, J. J. (2013). Financial declines, financial behaviors, and relationship happiness during the 2007-2009 recession. Journal of Financial Therapy, 4(1), 1-20. https://doi.org/10.4148/ jft.v4i1.1723

Douglas, M., Katikireddi, S. V., Taulbut, M., McKee, M., \& McCartney, G. (2020). Mitigating the wider health effects of COVID-19 pandemic response. BMJ. https://doi.org/10.1136/bmj.m1557

Falconier, M. K. (2015). Together: A couples' program to improve communication, coping, and financial management skills: Development and initial pilot-testing. Journal of Marital and Family Therapy, 41(2), 236-250.

Falconier, M. K., \& Epstein, N. B. (2011). Couples experiencing financial strain: What we know and what we can do. Family Relations, 60(3), 303-317. https://doi.org/10.1111/j.1741-3729.2011. 00650.x

Falconier, M. K., \& Jackson, J. B. (2020). Economic strain and couple relationship functioning: A meta-analysis. International Journal of Stress Management. https://doi.org/10.1037/str0000157

Friedline, T., \& Chen, Z. (2020). Families' Financial Stress \& WellBeing: The Importance of the Economy and Economic Environments. Journal of Family and Economic Issues, 2020, 1-18.

Grobbelaar, C., \& Alsemgeest, L. (2016). The relationship between spousal communication and financial arguments and stress between young married couples. Journal of Social Sciences, 46(3), 271-281.

Gudmunson, C. G., Beutler, I. F., Israelsen, C. L., McCoy, J. K., \& Hill, E. J. (2007). Linking financial strain to marital instability: Examining the roles of emotional distress and marital interaction. Journal of Family and Economic Issues, 28(3), 357-376. https:// doi.org/10.1007/s10834-007-9074-7

Hanspal, T., Weber, A., \& Wohlfart, J. (2020). Income and wealth shocks and expectations during the covid-19 pandemic. CESifo Working Paper, No. 8244, Center for Economic Studies and ifo Institute. http://hdl.handle.net/10419/216640

Heen, M., Lieberman, J., \& Miethe, T. (2014). A comparison of different online sampling approaches for generating national samples. Center for Crime \& Justice Policy, 1(9), 1-8.

Igielnik, R. (2020, May 15). Majority of Americans who lost a job or wages due to COVID-19 concerned states will reopen too quickly. Pew Research Center. https://www.pewresearch.org/fact-tank/ 2020/05/15/majority-of-americans-who-lost-a-job-or-wages-dueto-covid-19-concerned-states-will-reopen-too-quickly/

Kelley, H. H., LeBaron, A. B., \& Hill, E. J. (2018). Financial stress and marital quality: The moderating influence of couple communication. Journal of Financial Therapy, 9(2), 18-36. https://doi.org/ 10.4148/1944-9771.1176

Kelley, H. H., LeBaron, A. B., \& Hill, E. J. (2020). Family Matters: Decade Review from Journal of Family and Economic Issues. Journal of Family and Economic Issues. https://doi.org/10.1007/ s10834-020-09706-8

Kinnunen, U., \& Feldt, T. (2004). Economic stress and marital adjustment among couples: Analyses at the dyadic level. European 
Journal of Social Psychology, 34, 519-532. https://doi.org/10. 1002/ejsp.213

Lambert, N. M., Fincham, F. D., \& Stillman, T. F. (2012). Gratitude and depressive symptoms: The role of positive reframing and positive emotion. Cognition \& Emotion, 26(4), 615-633.

Lambert, N. M., Graham, S. M., Fincham, F. D., \& Stillman, T. F. (2009). A changed perspective: How gratitude can affect sense of coherence through positive reframing. The Journal of Positive Psychology, 4(6), 461-470.

Landis, J. R., \& Koch, G. G. (1977). The measurement of observer agreement for categorical data. Biometrics, 33(4), 159-174.

LeBaron, A. B., Curran, M. A., Li, X., Dew, J. P., Sharp, T. K., \& Barnett, M. A. (2020). Financial stressors as catalysts for relational growth: Bonadaptation among lower-income, unmarried couples. Journal of Family and Economic Issues, 41(1), 424-441. https:// doi.org/10.1007/s10834-020-09666-Z

LeBaron, A. B., Hill, E. J., Rosa, C. M., Spencer, T. J., Marks, L. D., \& Powell, J. T. (2018). I wish: Multi-generational regrets and reflections on teaching children about money. Journal of Family and Economic Issues, 39(2), 220-232. https://doi.org/10.1007/ s10834-017-9556-1

LeBaron, A. B., \& Kelley, H. H. (2020). Financial socialization: A decade in review. Journal of Family and Economic Issues, 2020, $1-12$.

LeBaron, A. B., Kelley, H. H., Hill, E. J., \& Galbraith, Q. (2019). Finances, religion, and the FAAR model: How religion exacerbates and alleviates financial stress. Advance Online Publication. https://doi.org/10.1037/rel0000294

Lebow, J. L. (2020). Family in the age of COVID-19. Family Process, 59(20), 309-312. https://doi.org/10.1111/famp.12543

Lee, C. Y. S., Lee, J., \& August, G. J. (2011). Financial stress, parental depressive symptoms, parenting practices, and children's externalizing problem behaviors: Underlying processes. Family Relations, 60(4), 476-490. https://doi.org/10.1111/j.1741-3729.2011. 00656.x

León, A. K., \& Pfeifer, C. (2017). Religious activity, risk-taking preferences and financial behaviour: Empirical evidence from German survey data. Journal of Behavioral and Experimental Economics, 69, 99-107. https://doi.org/10.1016/j.socec.2017.05.005

Long, H., \& Dam, A. V., (2020, April 9). America is in a depression. The challenge now is to make it short-lived. Washington Post. https://www.washingtonpost.com/business/2020/04/09/66-milli on-americans-filed-unemployed-last-week-bringing-pandemictotal-over-17-million/

Lusardi, A., Hasler, A., \& Yakoboski, P. J. (2020). Building up financial literacy and financial resilience. Mind \& Society. https://doi.org/ 10.1007/s11299-020-00246-0

Marks, L. D. (2015). A pragmatic, step-by-step guide for qualitative methods: Capturing the disaster and long-term recovery stories of Katrina and Rita. Current Psychology, 34(3), 494-505. https:// doi.org/10.1007/s12144-015-9342-x

Mao, D. (2017). Financial Stress, Parenting Quality, and the Moderating Effect of Co-parenting Alliance within the Marital Dissolution Population. Published Dissertation. https://conservancy.umn.edu/ bitstream/handle/11299/191495/Mao_umn_0130E_18548.pdf? sequence $=1 \&$ is Allowed $=\mathrm{y}$

Meade, A. W., \& Craig, S. B. (2012). Identifying careless responses in survey data. Psychological Methods, 17(3), 437.

Mistry, R. S., Lowe, E. D., Benner, A. D., \& Chien, N. (2008). Expanding the family economic stress model: Insights from a mixedmethods approach. Journal of Marriage and Family, 70, 196-209. https://doi.org/10.1111/j.1741-3737.2007.00471.x

NEFE. (2020, April 16). Survey: Nearly 9 in 10 Say COVID-19 Crisis is Causing Financial Stress. National Endowment for Financial Education. https://www.nefe.org/news/polls/2020/survey-covid19-crisisi-causing-financial-stress.aspx
Olson, J., \& Rick, S. (2018). Managing debt and managing each other: The interpersonal dynamics of joint financial decisions. Available at SSRN,. https://doi.org/10.2139/ssrn.2637637

Parker, K., Minkin, R., \& Bennet, J. (2020, September 24). Economic fallout from COVID-19 continues to hit lower-income Americans the hardest. Pew Research Center. https://www.pewresearch.org/ social-trends/2020/09/24/economic-fallout-from-covid-19-conti nues-to-hit-lower-income-americans-the-hardest/

Patterson, J. M. (1988). Families experiencing stress: I The Family Adjustment and Adaptation Response Model: II Applying the FAAR Model to health-related issues for intervention and research. Family Systems Medicine, 6(2), 202.

Pietromonaco, P. R., \& Overall, N. C. (2020). Applying relationship science to evaluate how the COVID-19 pandemic may impact couples' relationships. American Psychologist. https://doi.org/10. 1037/amp0000714

Prime, H., Wade, M., \& Browne, D. T. (2020). Risk and resilience in family well-being during the COVID-19 pandemic. American Psychologist, 75, 631-643. https://doi.org/10.1037/amp0000660

Qualtrics. (2021). Online sample. Qualtrics. https://www.qualtrics. com/research-services/online-sample/

Robila, M., \& Krishnakumar, A. (2005). Effects of economic pressure on marital conflict in Romania. Journal of Family Psychology, 19(2), 246. https://doi.org/10.1037/0893-3200.19.2.246

Stein, C. H., Hoffmann, E., Bonar, E. E., Leith, J. E., Abraham, K. M., Hamill, A. C., \& Fogo, W. R. (2013). The United States economic crisis: Young adults' reports of economic pressures, financial and religious coping and psychological well-being. Journal of Family and Economic Issues, 34(2), 200-210.

Stewart, R. C., Dew, J. P., \& Lee, Y. G. (2017). The association between employment- and housing-related financial stressors and marital outcomes during the 2007-2009 recession. Journal of Financial Therapy, 8(1), 43-61. https://doi.org/10.4148/1944-9771.1125

US Bureau of Labor Statistics. (2021, January 8). Table A-10. Selected unemployment indicators, seasonally adjusted. https://www.bls. gov/news.release/empsit.t10.htm

Vannette, D. (2017). Using attention checks in your surveys may harm data quality. https://www.qualtrics.com/blog/using-attentionchecks-in-your-surveys-may-harm-data-quality/

Vinokur, A. D., Price, R. H., \& Caplan, R. D. (1996). Hard times and hurtful partners: How financial strain affects depression and relationship satisfaction of unemployed persons and their spouses. Journal of Personality and Social Psychology, 71(1), 166. https:// doi.org/10.1037/0022-3514.71.1.166

Yoshikawa, H., Weisner, T. S., Kalil, A., \& Way, N. (2008). Mixing qualitative and quantitative research in developmental science: Uses and methodological choices. Developmental Psychology, 44(2), 344-354. https://doi.org/10.1037/0012-1649.44.2.344

Publisher's Note Springer Nature remains neutral with regard to jurisdictional claims in published maps and institutional affiliations.

Heather H. Kelley is a doctoral student in Human Development and Family Studies at Utah State University (USU). She is a recipient of USU's Presidential Doctoral Research Fellowship. She obtained her master's degree in Marriage, Family, and Human Development from Brigham Young University. Her research interests include family finance and more specifically, the impact of financial stress on family relationships.

Yoon Lee is a Professor in the Department of Human Development and Family Studies at Utah State University. She is a Consumer and Family economist interested in household debt, saving, and credit use decisions and relevant financial education and policy issues. Her research centers 
on family financial behaviors and issues, with an emphasis on women, millennials, minorities, and older adults.

Ashley LeBaron-Black is an Assistant Professor of Family Life at Brigham Young University in Provo, Utah. Her research focus is family finance, including couple finance and financial socialization. Ashley has published 35 peer-reviewed articles and is an Associate Editor for the Journal of Family and Economic Issues. She is Chair of the Family Financial Wellbeing focus group for the National Council on Family Relations (NCFR).

David C. Dollahite $\mathrm{PhD}$, is Camilla Eyring Kimball Professor of Family Life at Brigham Young University. He is Co-Director (with Loren Marks) of the American Families of Faith Project. He has more than 200 publications for scholarly and public audiences including eight edited or authored books including Strengths in Diverse Families of Faith (2020, Routledge), Religion and Families (2017, Routledge), Generative Fathering (Sage, 1998) and four volumes on LDS family life: Home-centered Religious Life (Deseret Book, in press) Successful Marriages and Families (BYU Studies, 2012), Helping and Healing Our Families (Deseret Book, 2005), and Strengthening Our Families (Bookcraft, 2000).

Spencer James is associate professor of Family Life and an Africana Studies affiliate at Brigham Young University. He directs the Global Families Research Initiative, which focuses on global family relationships and how those relationships influence the wellbeing of children, adolescents, and adults. Within this broader stream of research, he focuses on two lines: the first on the consequences of family relationships for child well-being, and the second addressing how and why people form, maintain, and dissolve romantic relationships. Currently, he is working on several projects that examine how family structure and child well-being are linked in sub-Saharan Africa.

Loren D. Marks is a professor in Brigham Young University's School of Family Life. His research interests include family finances and religion and families. He has authored about 150 scholarly works, including three books, Sacred Matters (2012, Routledge), Religion and Families (2017, Routledge), and Strengths of Diverse Families of Faith (2020, Routledge).

Tyler Hall is currently a master's student at the University of Southern Mississippi earning a degree Marriage and Family Therapy, where he has a full graduate assistantship. He received his bachelor's degree in percussion performance from Brigham Young University. His goals include becoming an LMFT and pursuing a doctoral program to become involved with university and community level family life education. 